\title{
MỐI QUAN HÊ GIŨ๋A DANH TIẾNG TRƯờnG ĐÄI HỌC, TÍNH CÁCH THƯONG HIỆ, GẮN KẾT THƯƠNG HIỆU VÀ LÒNG TRUNG THÀNH CỦA SINH VIÊN TẠI THÀNH PHỐ HỒ CHÍ MINH
}

\author{
TRỊNH ĐÀO VÂN ANH, NGUYẼ̃N NGỌC HIÊN \\ Khoa Quản trị kinh doanh, Truờng Đại học Công nghiệp Thành phố Hồ Chí Minh \\ nguyenngochien.qn@iuh.edu.vn
}

\begin{abstract}
Tóm tắt. Trong bối cảnh hội nhập ở Việt Nam, các trường đại học sử dụng thương hiệu để tăng lợi thế cạnh tranh thu hút những sinh viển tiềm năng và giữ chân các cựu sinh viên tiếp tục học tập tại trường với chương trình đào tạo cao hơn. Các tài liệu về thương hiệu trường đại học đã được phát triển. Tuy nhiên, nghiên cứu về danh tiếng trường đại học, tính cách thương hiệu vẫn còn mới tại môi trường tiếp thị giáo dục Việt Nam. Nghiên cứu này nhằm mục đích kiểm định mổi quan hệ nhân quả giữa danh tiểng trường đại học, tính cách thương hiệu, gắn kết thương hiệu cũng như tác động trung gian của sự hài lòng về lòng trung thành của sinh viên tại TP.HCM. Với mẫu là 250 sinh viên đại học được khảo sát trực tuyến qua biểu mẫu kết hợp với phân tích mô hình hồi quy bội. Kết quả từ nghiên cứu thực nghiệm cho thấy: danh tiếng thương hiệu, gắn kết thương hiệu, sự hài lòng tác động có ý nghĩa lên lòng trung thành của sinh viên. Sự hài lòng có tác động mạnh đển lòng trung thành của sinh viên, tiếp đến là danh tiếng trường đại học. Từ kết quả nghiên cứu, tác giả đề xuất hàm ý quản trị nhằm hỗ trợ các nhà quản trị thương hiệu tại trường đại học nâng cao sự hài lòng và lòng trung thành của sinh viên.
\end{abstract}

Từ khóa. Danh tiếng trường đại học, tính cách thương hiệu, gắn kết thương hiệu, sự hài lòng, lòng trung thành sinh viên

\section{THE RELATIONSHIP BETWEEN UNIVERSITY REPUTATION, BRAND PERSONALITY, BRAND ATTACHMENT AND STUDENT LOYALTY IN HO CHI MINH CITY}

\begin{abstract}
In the context of integration in Vietnam, universities use brands to increase their competitive advantage to attract potential students and retain alumni continuing to study at the university with higher training programs. The university branding literature has been developed. However, research on university reputation and brand personality is still new in the educational marketing environment in Vietnam. This study aims to examine the causal relationship between university reputation, brand personality, brand attachment, and the mediating effect of student loyalty satisfaction in Ho Chi Minh City. With a sample of 250 university students surveyed online through a form combined with multiple regression analysis. The results from the empirical research show that: brand reputation, brand attachment, satisfaction have a significant impact on student loyalty. Satisfaction has a strong impact on student loyalty, followed by university reputation. The author proposes governance implications to assist brand administrators in universities to improve student satisfaction and loyalty.
\end{abstract}

Keywords. University reputation, Brand attachment, Brand personality, Satisfaction, Student loyalty

\section{GIỚI THIỆ}

Theo thống kê của Bộ giáo dục và đào tạo năm 2019, hiện nay Việt Nam có đến 237 trường đại học, học viện (có 172 trường công lập, 60 trường tư thục, 5 trường có $100 \%$ vốn nước ngoài) chưa kể đến các trường trung cấp, cao đẳng và trung tâm đào tạo ngắn hạn với các chương trình đào tạo quốc tế. Các số liệu kể trên thể hiện sức cạnh tranh gay gắt trong môi trường giáo dục đại học. Theo Joseph và cộng sự (2012); Bock và cộng sự (2014), các trường đại học phải đối mặt với những thách thức đáng kể trong việc tuyển sinh viên mới. Sự cần thiết của việc quản lý tuyển sinh hiện có hơn là tranh giành cho tuyển sinh mới hơn cho vị trí mạnh mẽ hơn trên thị trường (Zemke, 2000; DeShields, 2005). Giáo dục đại học được thành lập như một hiện tượng toàn cầu, khiến nghiên cứu trong hoạt động tiếp thị của nó là không thể thiếu (Hemsley-Brown 
và Oplatka, 2006). Thương hiệu trường đại học được cho là tổng thể của nhận thức và cảm nhận của các bên liên quan về tổ chức (Hemsley-Brown và Oplatka 2006; Rauschnabel và cộng sự, 2016). Đối với các công ty và các trường đại học $(\mathrm{DH})$ lớn trên thế giới, sức mạnh của thương hiệu $(\mathrm{TH})$ uy tín đã trở thành vấn đề sống còn cho sự tồn tại và phát triển. Những thương hiệu của các công ty hàng đầu trên thế giới như Sony, Microsoft, Coca Cola... và của các trường đại học danh tiếng như Harvard, Cambridge... đã tạo được uy tín toàn cầu và chiếm được sự tin tưởng gần như tuyệt đối của khách hàng/sinh viên/các bậc phụ huynh khắp nơi trên thế giới (Đào Văn Khanh, 2004).

Những sinh viên hài lòng là chìa khóa để lan truyền những lời truyền miệng thuận lợi về các trường, thể hiện sự kết nối lòng trung thành được cải thiện và có nhiều khả năng hỗ trợ với tư cách là cựu sinh viên sau khi hoàn thành giáo dục (Wilkins và Balakrishnan, 2013). Do đó, khía cạnh này là một phần của hầu hết các cuộc điều tra thực nghiệm liên quan đến tiếp thị giáo dục đại học và vẫn là một cấu trúc quan trọng trong cuộc điều tra hiện tại.

Hội nhập quốc tế không chỉ mang lại những thách thức mà còn là động lực để thúc đẩy cạnh tranh giữa các doanh nghiệp, tập đoàn trong môi trường thương mại, trường học trong môi trường giáo dục. Để thu hút, đào tạo nguồn nhân lực tri thức trẻ và duy trì lòng trung thành của của họ là một yếu tố cấp thiết cần được quan tâm. Trong các bài báo nghiên cứu trước chủ yếu chỉ ra tầm quan trọng của việc xây dựng lòng trung thành sinh viên đối với thương hiệu, nghiên cứu khái quát độc lập nhân tố. Các nghiên cứu về danh tiếng thương hiệu, tính các thương hiệu với gắn kết thương hiệu và sự hài lòng của sinh viên chưa đo lường được mức độ tác động của nhân tố trên đến lòng trung thành của sinh viên tại các trường đại học khu vực TPHCM. Bài viết gồm 6 phần: Phần 1 giới thiệu tổng quan; phần 2 lược khảo lý thuyết về các khái niệm; phần 3 trình bày giả thuyết nghiên cứu và mô hình nghiên cứu, phần 3 trình bày phương pháp nghiên cứu; phần 5 phân tích kết quả nghiên cứu và thảo luận; và cuối cùng, phần 6 trình bày hàm ý quản trị hỗ trợ các nhà quản trị thương hiệu trường đại học đưa ra chiến lược phù hợp với cơ sở giáo dục của họ.

\section{CƠ SỞ LÝ THUYẾT}

\subsection{Danh tiếng trường đại học}

Lý thuyết danh tiếng trường đại học chủ yếu được xây dựng dựa trên các nghiên cứu hiện có về danh tiếng của công ty và có ảnh hưởng đáng kể từ các nghiên cứu tiếp thị giáo dục đại học. Các học giả vẫn đang tranh cãi về định nghĩa của danh tiếng doanh nghiệp và họ vẫn chưa đạt được sự đồng thuận (Clardy, 2012; Dowling, 2016). Đó là bởi vì các tổ chức theo hướng dịch vụ, chẳng hạn như các trường đại học dễ bị mất danh tiếng hơn nếu chất lượng không được quản lý hiệu quả, do danh tiếng này có vai trò chiến lược trong một tương lai bền vững cho các cơ sở giáo dục đại học (Su và cộng sự, 2016). Trong quản lý dịch vụ giáo dục, các khái niệm danh tiếng được sử dụng rộng rãi như công cụ định vị để ảnh hưởng đến việc sinh viên lựa chọn một cơ sở giáo dục đại học (Nguyen \& LeBlanc, 2001). Sinh viên có thể đã hình thành nhận thức về cả trường học và chương trình học cụ thể của họ. Quản lý danh tiếng cũng được coi là rất quan trọng để thu hút và giữ chân sinh viên (Standifird, 2005). Danh tiếng của một cơ sở giáo dục là những yếu tố ảnh hưởng mạnh nhất đến việc lựa chọn trường của sinh viên (Wilkins \& Huisman, 2011).

\subsection{Tính cách thương hiệu}

Tính cách thương hiệu là một tập hợp các đặc điểm của con người, được gán cho thương hiệu công ty đối với thương hiệu con người (Bekk và Spörrle 2010). Các kích thước tính cách thương hiệu được phát hiện có ảnh hưởng trực tiếp đến khách hàng lòng trung thành (Das 2014), tin tưởng (Louis và Lombart, 2010; Rampl và Kenning, 2014) và sự hài lòng (Rampl và Kenning 2014). Những tác động này chủ yếu là tích cực với tính cách thương hiệu mạnh hơn dẫn đến nhiều lòng trung thành hơn và mức độ tin cậy cao hơn và sự thỏa mãn

Công trình nghiên cứu về tính cách thương hiệu của Aaker (1997) kể từ đó đã truyền cảm hứng và hướng dẫn nhiều nhà nghiên cứu trong hành trình giải mã những cấu tạo mơ hồ của các thương hiệu sản phẩm và dịch vụ. Tính cách thương hiệu được định nghĩa chính thức ở đây là "tập hợp của các đặc điểm của con người gắn liền với thương hiệu. Tính cách thương hiệu đại diện cho một thước đo có khả năng nắm bắt các bên liên quan gắn bó với trường đại học (Blackston, 1993). Dựa theo Watkins và Gonzenbach (2013), áp dụng tính cách thương hiệu lên cao hơn tài liệu giáo dục cho phép các tổ chức tạo ra sự khác biệt của thương hiệu và sự khác biệt. Sung và Yang (2008) đánh giá tính cách thương hiệu là một phần của hình ảnh trường 
đại học tổng thể và xác định ảnh hưởng tích cực của hình ảnh trường đại học về thái độ ủng hộ của sinh viên đối với trường.

\subsection{Gắn kết thương hiệu}

Park và cộng sự, (2010) Sự gắn kết với thương hiệu, bao gồm sự kết nối thương hiệu và sự ủng hộ của thương hiệu có nghĩa là khách hàng gắn kết với sản phẩm hoặc thương hiệu về mặt cảm xúc (Jahn và cộng sự, 2012) và đóng vai trò quan trọng trong việc thiết lập mối quan hệ giữa các thương hiệu và người tiêu dùng (Veloutsou, 2015; Loureiro và cộng sự, 2017). Gắn kết thương hiệu biểu thị rằng mọi người liên kết thương hiệu một cách vui vẻ và cảm xúc (Escalas \& Bettman, 2003). Sự nổi bật của thương hiệu là cường độ của mối liên kết giữa thương hiệu và người tiêu dùng (Park và cộng sự, 2010).

Sự gắn kết dẫn đến một cam kết mạnh mẽ và có thể ảnh hưởng đến tình yêu và niềm đam mê khi các mối quan hệ đó rất bền chặt; do đó, điều đó khiến khách hàng thực sự trung thành và tạo cho anh ta niềm đam mê với thương hiệu (Loureiro và cộng sự, 2012). Sự gắn kết có thể vượt ra ngoài bối cảnh mối quan hệ giữa người với người (Belk, 1988).

\subsection{Sự hài lòng}

Sự hài lòng đã được định nghĩa là nhận thức về sự thỏa mãn một cách thú vị đối với một dịch vụ (Oliver, 1997). Về mặt hoạt động, cấu trúc tương tự như một thái độ vì nó có thể được đánh giá là tổng của sự hài lòng với các thuộc tính khác nhau của một sản phẩm hoặc dịch vụ (Churchill \& Surprenant, 1982). Kotler và Clarke (1987) định nghĩa sự hài lòng là kết quả mong muốn của một nhiệm vụ hoặc công việc làm hài lòng sự tôn trọng của một người. Theo Zeithaml (1988), sự hài lòng đóng một vai trò quan trọng trong việc xác định tính nguyên bản và tính chính xác của một hệ thống, đặc biệt là hệ thống giáo dục vì mức độ hài lòng càng cao sẽ là mức độ chuẩn bị cho sự phát triển kỹ năng, kiến thức và tâm lý của sinh viên. Vì sinh viên sẽ hài lòng hơn và có động lực hoàn thành chương trình học của mình nếu cơ sở giáo dục cung cấp một môi trường tạo điều kiện cho việc học tập, tức là cơ sở giáo dục có cơ sở hạ tầng phù hợp cho tiện ích giáo dục được tích lũy với các thông số thiết yếu về phát triển chuyên môn và học thuật.

Mức độ hài lòng được xác định bởi sự khác biệt giữa hiệu suất dịch vụ như được khách hàng cảm nhận và những gì khách hàng mong đợi (Parasuraman và cộng sự, 1986). Mặc dù có một số biến đáng kể có thể ảnh hưởng đến học sinh hiệu suất được cảm nhận và do đó hài lòng / không hài lòng (ví dụ: dịch vụ sinh viên và các hoạt động, v.v.), các dịch vụ cốt lõi do tổ chức cung cấp thường là hướng dẫn, lời khuyên và lời khuyên sinh viên. Do đó, hiệu suất của giảng viên, các lớp học và tư vấn hiệu suất của nhân viên là những yếu tố chính mà nghiên cứu này tập trung vào để ảnh hưởng đến sinh viên sự hài lòng / không hài lòng với giáo dục đại học. Có ý kiến cho rằng những học sinh có những trải nghiệm tích cực ở trường đại học sẽ hài lòng hơn những sinh viên không có một kinh nghiệm đại học tích cực. Do đó, sự hài lòng sẽ ảnh hưởng đến học sinh ý định ở lại hoặc rời khỏi trường

\subsection{Lòng trung thành sinh viên}

Lòng trung thành của khách hàng được thể hiện theo những cách khác nhau bao gồm cam kết mua lại hoặc bảo trợ cho một sản phẩm ưu tiên sản phẩm hoặc dịch vụ (Oliver, 1997) và lòng trung thành của khách hàng có tác động lâu dài với cơ sở giáo dục. Sinh viên trung thành đang ảnh hưởng tích cực đến chất lượng giảng dạy thông qua sự tham gia tích cực và một hành vi cam kết (Rodie và Kleine, 2000). Có lẽ họ là những người ủng hộ tốt, giới thiệu tổ chức cho những người khác. Bên cạnh đó, ngày càng có nhiều học sinh cũ quay trở lại trường cao hơn các cơ sở giáo dục để cập nhật kiến thức của họ (Marzo Navarro và cộng sự, 2005). Trong nghiên cứu của Nguyen và LeBlanc (2001), lòng trung thành được đo lường bởi ý định của sinh viên để: coi trường kinh doanh là sự lựa chọn đầu tiên của anh ấy / cô ấy để giáo dục, để tiếp tục chương trình tại trường kinh doanh và có ý định khuyến khích bạn bè học tại trường kinh doanh cũng như ý định giới thiệu nó là tốt nhất trong khu vực của nó.Tương tự như vậy, đối với Athiyaman (1997), lòng trung thành là sự kết hợp giữa học sinh sẵn sàng nói chuyện tích cực về tổ chức và cung cấp thông tin mới các ứng cử viên.

\section{GIẢ THUYẾT VÀ MÔ HÌNH NGHIÊN CỨU}

\subsection{Giả thuyết nghiên cứu}

Danh tiếng của tổ chức đã được nghiên cứu như một tiền thân hoặc trung gian của các cấu trúc liên quan đến việc đánh giá của các tổ chức, sản phẩm hoặc dịch vụ riêng lẻ hoặc cùng với sự hài lòng (Abdullah và 


\section{MỐI QUAN HỆ GIỮA DANH TIẾNG TRƯÒ̀NG ĐẠI HỌC, TÍNH CÁCH THƯƠNG HIỂU, GẤN KẾT THƯƠNG HIÊUU VÀ LÒNG TRUNG THÀNH CỦA SINH VIÊN TẠI THÀNH PHỐ HỔ CHÍ MINH}

cộng sự, 2000). Barich và Kotler (1991) cho rằng các công ty có một danh tiếng mạnh mẽ nếu khách hàng tin rằng họ nhận được giá trị tốt trong các giao dịch của họ với công ty. Nhận thức thuận lợi về danh tiếng được cho là có liên quan tích cực đến lòng trung thành (MacMillan và cộng sự, 2005).

Danh tiếng của tổ chức tích cực khuyến khích kỳ vọng về các sản phẩm và dịch vụ tốt hơn, điều này dẫn đến tăng sự hài lòng của khách hàng (Chang, 2013). Trích dẫn hàm ý của lý thuyết cân bằng, Chang (2013) cũng cho rằng thái độ tích cực đối với tổ chức làm tăng triển vọng hài lòng của khách hàng. Ảnh hưởng của danh tiếng đển sự hài lòng cũng được thể hiện rõ ràng trong các công trình của Helm và cộng sự, (2010). Helm và cộng sự, (2010) cũng duy trì rằng danh tiếng của công ty quyết định lòng trung thành của khách hàng. Dựa trên mối quan hệ danh tiếng - lòng trung thành, ảnh hưởng của danh tiếng trường đại học đến hành vi hỗ trợ của sinh viên (Sung và Yang, 2008) bổ sung thêm liên quan đến lập luận coi danh tiếng là yếu tố ảnh hưởng đến lòng trung thành của sinh viên. Do đó, các giả thuyết sau đã được đề xuất:

$\mathrm{H}_{1}$ : Danh tiếng trường đại học có ảnh hưởng tích cực đến sự hài lòng $\left(\mathrm{H}_{1 \mathrm{a}}\right)$ và ảnh hưởng tích cực đến lòng trung thành của sinh viên $\left(\mathrm{H}_{1 b}\right)$

Sự gắn kết với thương hiệu, bao gồm sự kết nối thương hiệu và sự ủng hộ của thương hiệu (Park và cộng sự, 2010), có nghĩa là khách hàng gắn bó với sản phẩm hoặc thương hiệu về mặt cảm xúc (Jahn và cộng sự, 2012) và đóng vai trò quan trọng trong việc thiết lập mối quan hệ giữa các thương hiệuvà người tiêu dùng (Veloutsou,2015; Loureiro và cộng sự, 2017). Kết nối thương hiệu biểu thị rằng mọi người liên kết thương hiệu vui vẻ và cảm xúc (Escalas \& Bettman, 2003). Sự nổi bật của thương hiệu là cường độ của mối liên kết giữa thương hiệu và người tiêu dùng (Park và cộng sự, 2010). "Sự gắn kết với một địa điểm dẫn đến những đánh giá thuận lợi của các cá nhân về bầu không khí và dịch vụ tổng thể của địa điểm đó (Yuksel và cộng sự, 2010). Các nghiên cứu từ nghiên cứu về sự gắn kết với địa điểm cho thấy tác động tích cực của sự gắn kết của người trả lời đối với sự hài lòng (Veasna và cộng sự, 2013). Fleury Bahi và cộng sự (2008) cũng ghi nhận mối liên hệ chặt chẽ hơn giữa sự hài lòng của các cá nhân và sự gắn kết của họ với nơi lưu trú. Trong mô hình mở rộng tài sản thương hiệu trường đại học, Dennis và cộng sự (2016) nhận thấy ảnh hưởng đáng kể của việc gắn kết thương hiệu trường đại học đến sự hài lòng của sinh viên. Những nỗ lực để hình thành khái niệm gắn kết thương hiệu trong bối cảnh trường đại học vẫn còn non trẻ và cần được điều tra thêm, cũng bởi vì sự gắn kết thương hiệu vẫn là một khái niệm được nghiên cứu nhiều trong tiếp thị và thể hiện những tác động có thể nghiên cứu giáo dục, như đã thấy rõ trong nghiên cứu được thực hiện bởi Dennis và cộng sự (2016). Hơn nữa, sự gắn kêt với thương hiệu cũng đã được chứng minh là ảnh hưởng đến lòng trung thành của khách hàng trong các bối cảnh đa dạng (Yuksel và cộng sự, 2010; Nyadzayo và cộng sự, 2018). Dựa trên các lập luận đã trình bày ở trên, các giả thuyết sau được đưa ra:

$\mathrm{H}_{2}$ : Gắn kết thương hiệu có ảnh hưởng tích cực đến sự hài lòng $\left(\mathrm{H}_{2 \mathrm{a}}\right)$ và ảnh hưởng tích cực đến lòng trung thành của sinh viên $\left(\mathrm{H}_{2 b}\right)$.

Thang đo tính cách thương hiệu của Aaker (1997) thường được sử dụng để đánh giá nhận thức về thương hiệu. Theo ông, tính cách thương hiệu là "tập hợp các đặc điểm của con người gắn liền với thương hiệu" (trang 347 ), được phát triển dựa trên trải nghiệm trực tiếp và gián tiếp của người tiêu dùng với thương hiệu. Tính cách thương hiệu có thể được tạo ra từ các yếu tố liên quan đến phi sản phẩm, ví dụ: kinh nghiệm trong quá khứ, truyền thông tiếp thị, truyền miệng, cũng như các yếu tố liên quan đến sản phẩm, ví dụ: chủng loại sản phẩm, giá cả và các thuộc tính vật lý. Tương tự, sử dụng phương pháp nhân cách hóa. Davies (2004) đã phát triển đặc điểm của công ty và đo lường danh tiếng của một công ty từ cả quan điểm nội bộ (nhân viên) và bên ngoài (khách hàng).

Ở cấp độ dân trí, thật hấp dẫn khi "những vật mang tính biểu tượng không phải của con người như thương hiệu” (Aaker và cộng sự, 2001) lại được người tiêu dùng nhân cách hóa (Caprara và cộng sự, 2001).Tính cách là một phép ẩn dụ được khai thác nhiều trong xây dựng thương hiệu doanh nghiệp, nơi nó được liên kết với việc đánh giá thương hiệu của công ty (Sung và Yang, 2008).Tính cách thương hiệu mạnh sẽ ảnh hưởng đến hành vi mua lại của khách hàng đồng thời giảm thiểu rủi ro cảm xúc và tạo ra sự hài lòng về sản phẩm hoặc dịch vụ (Chen và Phou, 2013). Các quan sát tương tự được thực hiện bởi Sirgy (1982) xác nhận vai trò của tính cách thương hiệu trong việc tác động có lợi đển hành vi ưa thích và bảo trợ của khách hàng. Chen và Phou (2013) khẳng định rằng, trong khi xem xét các cấu trúc học tập từ hành vi của khách du lịch từ góc độ tiếp thị, các cá nhân bị ảnh hưởng bởi tính cách thương hiệu của điểm đến ngay cả trước khi tiêu dùng thực tế. Đối với sinh viên giáo dục đại học, thương hiệu hoặc tính cách trường đại học cũng ảnh hưởng 
đến việc đánh giá tinh thần của họ trước khi đăng ký vào các trường đại học, điều này tiếp tục phát triển trong và sau nhiệm kỳ giáo dục (Dennis và cộng sự, 2016). Với những lập luận này, các giả thuyết sau đây: $\mathrm{H}_{3}$ : Tính cách thương hiệu có ảnh hưởng tích cực đến sự hài lòng $\left(\mathrm{H}_{3 \mathrm{a}}\right)$ và ảnh hưởng tích cực đến lòng trung thành của sinh viên $\left(\mathrm{H}_{3 \mathrm{~b}}\right)$.

Nhiều nghiên cứu đã xem xét sự hài lòng lòng trung thành của khách hàng theo cách nhìn của tiếp thị. Mặc dù một có thể ngại gọi học sinh là "khách hàng" vì mối quan hệ giữa học sinh - giáo viên, thực tế là không có học sinh, sẽ không cần các cơ sở giáo dục. Cho nên, hiểu biết về mối liên hệ giữa sự hài lòng của sinh viên, nhận thức về tổ chức và lòng trung thành với vấn đề sẽ giúp các trường đại học đưa ra các chiến lược hoạt động xuất sắc.

Sự hài lòng của khách hàng đã được coi là một tiền đề của hành vi mua hàng lặp lại của khách hàng, tăng doanh thu và thị phần (Su và cộng sự. 2016; Koklic và cộng sự. 2017). Sự hài lòng như một khía cạnh trong các nghiên cứu xây dựng thương hiệu cũng đã được nghiên cứu như một yếu tố trung gian quan trọng giữa các yếu tố khác nhau về lòng trung thành (Yuksel và cộng sự 2010; Su và cộng sự 2016). Mức độ hài lòng được xác định bởi sự khác biệt giữa hiệu suất dịch vụ như được khách hàng cảm nhận và những gì khách hàng mong đợi (Parasuraman và cộng sự, 1986). Có ý kiến cho rằng những học sinh có những trải nghiệm tích cực ở trường đại học sẽ hài lòng hơn những sinh viên không có một trải nghiệm đại học tích cực. Do đó, sự hài lòng sẽ ảnh hưởng đến học sinh ý định ở lại hoặc rời khỏi trường. Vì thế:

$\mathrm{H}_{4}$ : Sự hài lòng của sinh viên ảnh hưởng tích cực đến lòng trung thành của sinh viên.

\subsection{Mô hình nghiên cứu}

Mô hình được sử dụng để kiểm tra mối quan hệ giữa các biến danh tiếng của trường đại học, sự gắn kết với thương hiệu trường đại học, tính cách thương hiệu, sự hài lòng của sinh viên, và lòng trung thành của sinh viên. Các câu trả lời về mặt hàng được đưa ra theo thang điểm Likerttype năm điểm, từ "hoàn toàn không đồng ý" đến "hoàn toàn đồng ý" (Hình 1).

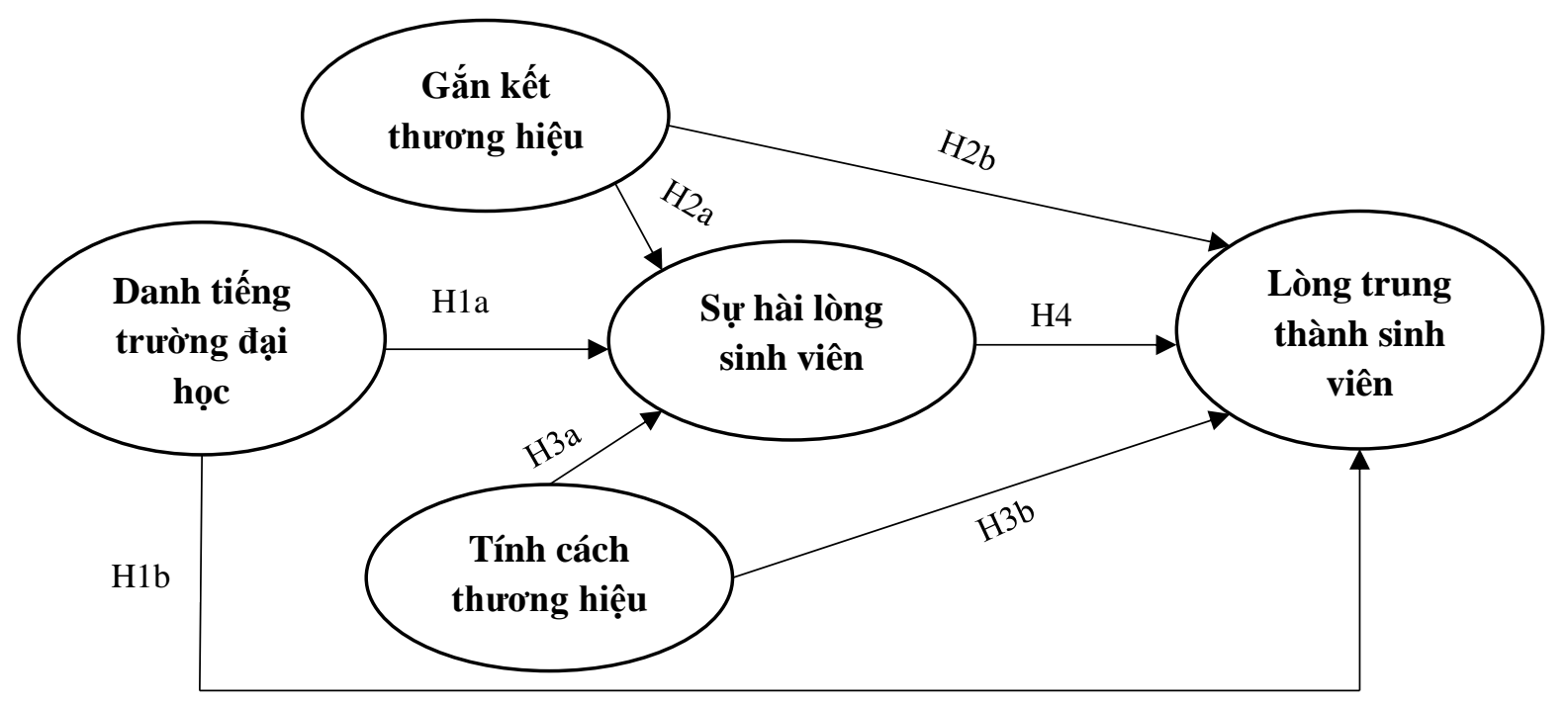

Hình 1: Mô hình nghiên cứu đề xuất

(Nguồn: Tác giả tổng hợp)

\section{PHƯƠNG PHÁP NGHIÊN CÚU}

\section{1. Đo lường}

Nghiên cứu này sử dụng thang đo lường của các nghiên cứu trước đã kiểm định trong những bối cảnh khác nhau và điều chỉnh thang đo gốc để phù hợp hơn với thực tế. Tất cả các thang đo các cấu trúc được đo lường bằng thang đo likert 5 điểm từ Rất không đồng ý (1) đến Rất đồng ý (5). Ngoài ra, bảng câu hỏi cũng bao gồm bốn câu hỏi về nhân khẩu học liên quan đến tuổi tác, giới tính, trình độ học vấn, trường đại học sinh viên đang theo học. 
176 MỐI QUAN HỆ GIŨA DANH TIÊNG TRƯỜNG ĐẠI HỌC, TÍNH CÁCH THƯƠNG HIẸU, GẮN KẾT THƯƠNG HIỆU VÀ LÒNG TRUNG THÀNH CỦA SINH VIÊN TẠI THÀNH PHỐ HỔ CHÍ MINH

Bảng 1: Thang đo lường và nguồn tham khảo

\begin{tabular}{|c|c|}
\hline Khái niệm và biến quan sát & Nguồn \\
\hline $\begin{array}{l}\text { Danh tiếng trường đại học (University Reputation) } \\
\text { DTTDT1. Tôi nhận thấy trường đại học mà tôi đang theo học có một danh tiếng tốt } \\
\text { DTTDT2. Tôi tin danh tiếng của trường đại học mà tôi đang học tốt hơn các trường đại học khác } \\
\text { DTTDT3. Tôi cảm thấy bằng cấp được cấp từ trường ĐH của tôi được đánh giá cao hơn các trường } \\
\text { ĐH khác } \\
\text { DTTDT4. Trường đại học tôi đang theo học có triển vọng phát triển mạnh trong tương lai }\end{array}$ & $\begin{array}{l}\text { Nguyen and } \\
\text { LeBlanc } \\
\text { (2001); Sung } \\
\text { and Yang } \\
\text { (2008) }\end{array}$ \\
\hline $\begin{array}{l}\text { Sự gắn kết thương hiệu (Brand Attechment) } \\
\text { GKTH1. Tôi tự hào khi có ai đó khen trường mà tôi đang theo học } \\
\text { GKTH2. Tôi cảm thấy gắn bó với thầy cô } \\
\text { GKTH3. Tôi tự hào khi là sinh viên của trường } \\
\text { GKTH4. Tôi tự hào về chương trình đào tạo tại trường }\end{array}$ & $\begin{array}{c}\text { Mael \& } \\
\text { Ashforth } \\
\text { (1992); Dennis } \\
\text { \& cộng sự, } \\
\text { (2016) }\end{array}$ \\
\hline $\begin{array}{l}\text { Tính cách thương hiệu (Brand Personnality) } \\
\text { TCTH1. Tôi cảm thấy thương hiệu trường đại học của tôi thân thiện } \\
\text { TCTH2. Tôi cảm thấy thương hiệu trường đại học của tôi thực tế } \\
\text { TCTH3. Tôi cảm thấy thương hiệu trường đại học của tôi thể hiện tính chân thành } \\
\text { TCTH4. Tôi cảm thấy thương hiệu trường đại học của tôi thể hiện tính thú vị } \\
\text { TCTH5. Tôi cảm thấy thương hiệu trường đại học của tôi thẩm quyền } \\
\text { TCTH6. Tôi cảm thấy thương hiệu trường đại học của tôi thể hiện tính tiến bộ }\end{array}$ & $\begin{array}{c}\text { Aaker (1997), } \\
\text { Sung và Yang } \\
\text { (2008), } \\
\text { Rauschnabel } \\
\quad(2016)\end{array}$ \\
\hline $\begin{array}{l}\text { Sự hài lòng (Satisfaction) } \\
\text { SHL1. Tôi cảm thấy quyết định đúng khi chọn trường mà tôi đang theo học } \\
\text { SHL2. Các phương pháp giảng dạy trong lớp được phù hợp với thực tế } \\
\text { SHL3. Khi có thắc mắc tôi nhận được phản hồi nhanh chóng từ giảng viên } \\
\text { SHL4. Tôi nhận thấy chất lượng bài giảng trên lớp cung cấp đủ kiến thức cho tôi }\end{array}$ & $\begin{array}{c}\text { Athiyaman } \\
\text { (1997), } \\
\text { Helgesen and } \\
\text { Nesset (2007) }\end{array}$ \\
\hline $\begin{array}{l}\text { Lòng trung thành sinh viên (Student loyalty) } \\
\text { LTT1. Tôi dự định sẽ tiếp tục học lên cao học tại trường } \\
\text { LTT2. Tôi sẽ giới thiệu thông tin trường cho sinh viên tiềm năng } \\
\text { LTT3. Tôi sẽ hỗ trợ trường với tư cách là cựu sinh viên } \\
\text { LTT4. Đề xuất chương trình, các hoạt động giáo dục để nhà trường hoàn thiện hơn }\end{array}$ & $\begin{array}{c}\text { Alves và } \\
\text { Raposo (2006), } \\
\text { Alves và } \\
\text { Raposo (2010) }\end{array}$ \\
\hline
\end{tabular}

\subsection{Thu thập dữ liệu}

(Nguồn: Tác giả điều chỉnh tù thang đo của nghiên cúu trước)

Nghiên cứu định lượng sơ bộ được thực hiện vào tháng 3 năm 2021 nhằm mục đích kiểm tra lại nội dung và cấu trúc của bảng câu hỏi. Người trả lời các câu hỏi được yêu cầu trả lời tất cả các câu hỏi và phản hồi ý kiến xem đã hiểu câu hỏi chưa hoặc cần bổ sung yếu tố nào để hoàn thiện thang đo. Kết quả khảo sát 50 sinh viên đang học tại các trường đại học tại $\mathrm{Tp}$. Hồ Chí Minh cho thấy rằng, từ ngữ các thang đo cần được điều chỉnh để phù hợp với bối cảnh ngành giáo dục tại $\mathrm{Tp}$. Hồ Chí Minh, đặc biệt một số từ ngữ trong thang đo tính cách thương hiệu, tác giả đã chỉnh sửa theo góp ý của người trả lời và các chuyên gia trong lĩnh vực giáo dục, kết quả thể hiện trong bảng 1 .

Nghiên cứu định lượng chính thức được thực hiện thông qua bảng câu hỏi ccấu trúc, bảng câu hỏi được phân phối trực tuyến thông qua các trang mạng xã hội và email. Đối tượng mẫu khảo sát là sinh viên đang học năm 3 và năm 4 tại các trường Đại học tại TP. Hồ Chí Minh. Theo Hair \& cộng sự (2010) kích thước mẫu phải đạt được ít nhất 5 lần số biến quan sát và gấp 10 lần là tốt nhất. Trong thang đo của nghiên cứu này có 22 biến quan sát, vì vậy kích thước mẫu tối thiểu của nghiên cứu này là $22 * 10=220$. Cỡ mẫu được thực hiện trong nghiên cứu này là 250 . 
MỐI QUAN HỆ GIŨ๋A DANH TIÊNG TRƯỜNG ĐẠI HỌC, TÍNH CÁCH THƯƠNG HIẸU, GẮN KẾT 177

THƯƠNG HIÊU VÀ LÒNG TRUNG THÀNH CỦA SINH VIÊN TAII THÀNH PHỐ HỔ CHÍ MINH

\section{KẾT QUẢ VÀ THẢO LUẬN}

\subsection{Kết quả nghiên cứu}

\subsection{1. Đặc điểm mẫu thống kê}

Bảng 2. Đặc điểm mẫu thống kê $(\mathrm{n}=250)$

\begin{tabular}{|c|c|c|c|}
\hline Đặc điểm cá nhân & Chi tiết & Số lượng & Tỷ lệ $(\%)$ \\
\hline \multirow{2}{*}{ Giới tính } & Nam & 127 & 50.8 \\
& Nữ & 123 & 49.2 \\
\hline \multirow{3}{*}{ Trường } & Đại học Công Nghiệp Tp.HCM & 45 & 18.0 \\
& Đại học Bách Khoa Tp.HCM & 33 & 13.2 \\
& Đại học Kinh Tế Tp.HCM & 34 & 13.6 \\
& Đại học Hoa Sen & 36 & 14.4 \\
& Đại học Tôn Đức Thắng & 41 & 13.2 \\
& Đại học RMIT & 33 & 9.2 \\
\hline \multirow{2}{*}{ Sinh viên năm } & Đại học Văn Lang & 23 & 2.0 \\
\hline & Khác & 5 & 21.2 \\
\hline
\end{tabular}

(Nguồn: Tác giả tổng hơp tù̀ dũ liệu khảo sát)

Số liệu của 250 người khảo sát (bảng 2) cho thấy tỷ lệ giới tính nam cao hơn so với nữ $(50.8 \%>49.2 \%)$. Trình độ học vấn đều là đại học, đa phần là sinh viên năm 3 và 4 (chiếm lần lượt là $21.2 \%$ và $78.8 \%$ ) đã có thời gian trải nghiệm, gắn bó tại trường đại học của mình.

\subsubsection{Kiểm định độ tin cậy thang đo}

Từ kết quả kiểm đinh độ tin cậy của thang đo (bảng 3) bằng phần mền SPSS 20 cho thấy, các hệ số Cronbach's alpha của các thang đo thành phần đều đạt giá trị từ 0.765 đến 0.888 . Trong đó, thang đo danh tiếng trường đại học đạt độ tin cậy cao nhất là 0.888 , Tính cách thương hiệu đạt độ tin cậy thấp là 0.765 . Thang đo thành phần được thể hiện bằng 22 biến quan sát, hệ số tương quan biến tổng của các biến quan sát đều lớn hơn 0.3 đạt yêu cầu và có thể sử dụng cho phân tích nhân tố khám phá EFA.

Bảng 3. Độ tin cậy của thang đo

\begin{tabular}{|c|r|r|}
\hline Thang đo thành phần & Hệ số Cronbach's alpha & Hệ số tương quan biến-tổng \\
\hline Danh tiếng trường đại học & 0.888 & $\geq 0.717$ \\
\hline Gắn kết thương hiệu & 0.855 & $\geq 0.668$ \\
\hline Tính cách thương hiệu & 0.765 & $\geq 0.385$ \\
\hline Sự hài lòng & 0.817 & $\geq 0.603$ \\
\hline Lòng trung thành & 0.858 & $\geq 0.676$ \\
\hline
\end{tabular}

\subsubsection{Kết quả phân tích nhân tố khám phá EFA}

(Nguồn: Tác giả tổng hợp tù dũ liệu khảo sát)

Sau khi phân tích hệ số Cronbach's alpha của các nhân tố thỏa điều kiện, tiến hành chạy phân tích nhân tố khám phá. Kết quả chạy lần một loại 3 biến TCTH1, TCTH2, TCTH3 vì hệ số tải < 0.5 không đạt yêu cầu. Sử dụng phương pháp kiểm định Principal Axis factor với phép quay Promax. Kết quả thể hiện ở bảng 4 sau khi đã loại TCTH1,2,3 có hệ số eigenvalue $1.140>1$ là trong 22 biến quan sát trích được 5 nhân tố với dộ tin cậy là $70,913 \%>50 \%$. Điều này chứng tỏ $70,913 \%$ biến thiên của dữ liệu được giải thích bởi 5 nhân tố, tất cả hệ số tải đều > 0.5 không có biến loại, như vậy các biến quan sát này có ý nghĩa đóng góp vào mô hình. Kiểm định Bartlett's Test có ý nghĩa thống kê Sig $=0.00<0.05$ và hệ số KMO là 0.898 .

Bảng 4. Kết quả phân tích nhân tố EFA chạy lần 2

\begin{tabular}{|c|c|c|c|c|c|}
\hline \multirow{2}{*}{ Biến quan sát } & \multicolumn{5}{|c|}{ Nhân tó́ } \\
\cline { 2 - 6 } & 1 & 2 & 3 & 4 & 5 \\
\hline DTTDH1 & 0.841 & & & & \\
\hline DTTDH2 & 0.834 & & & & \\
\hline DTTDH3 & 0.814 & & & & \\
\hline DTTDH4 & 0.757 & & & & \\
\hline GKTH1 & & 0.829 & & & \\
\hline
\end{tabular}


178 MỐI QUAN HỆ GIŨ๋A DANH TIẾNG TRƯỜNG ĐẠI HỌC, TÍNH CÁCH THƯƠNG HIẸU, GẮN KẾT THƯƠNG HIỆU VÀ LÒNG TRUNG THÀNH CỦA SINH VIÊN TẠI THÀNH PHỐ HỔ CHÍ MINH

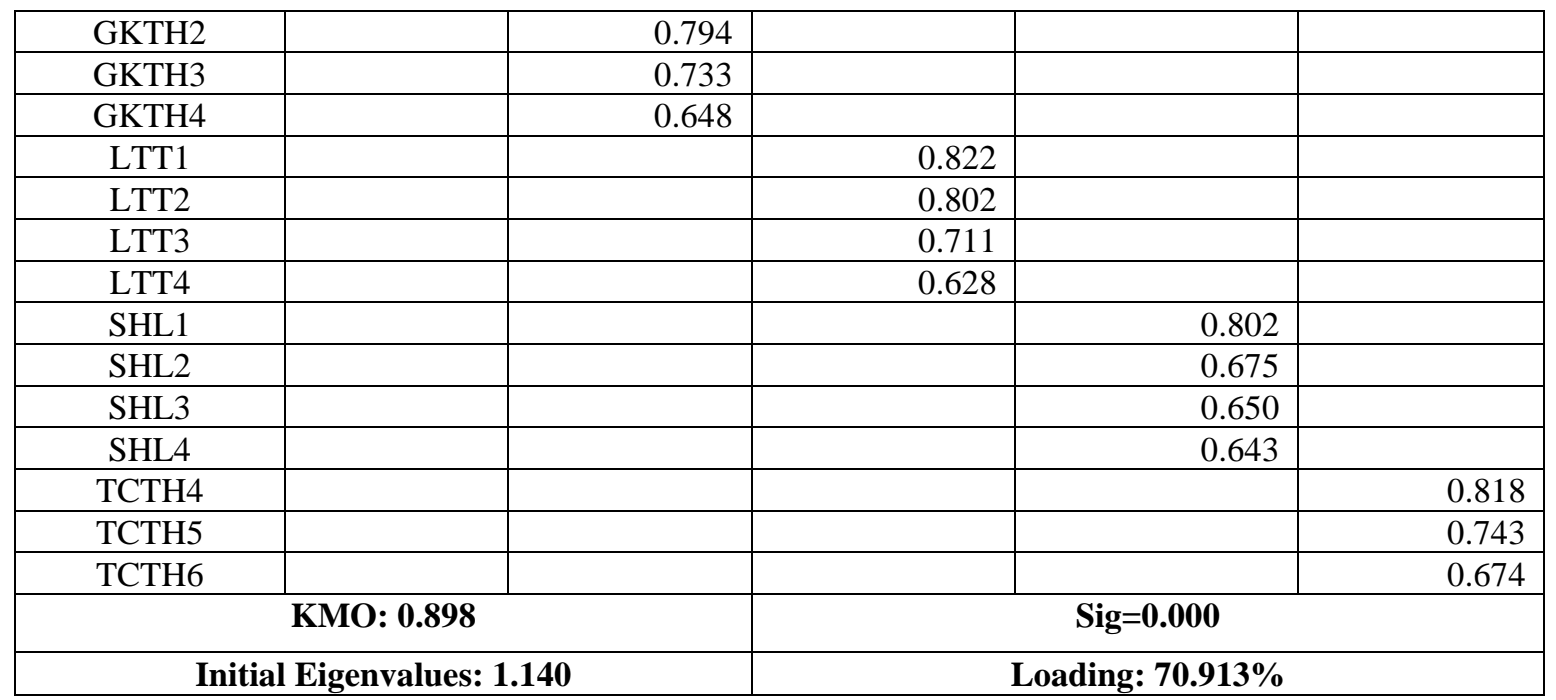

(Nguồn: Tác giả tổng hợp tù dũ liệu khảo sát)

\subsubsection{Kết quả phân tích nhân tố khẳng định CFA}

Kết quả phân tích nhân tố khẳng định (CFA) bằng phần mềm Amos 20.0 thể hiện mô hình này phù hợp với dữ liệu thị trường $($ Chi-square $=196.618 / \mathrm{df}=1.356<3 ; \mathrm{CFI}=0.978>0.9 ; \mathrm{GFI}=0.925>0.9 ; \mathrm{TLI}=0.974$ $>0.9$ và $\mathrm{RMSEA}=0.038<0.08$ ). Trọng số chuẩn hóa của các biến quan sát lớn hơn $0.540 \geq 0.5$ đều đạt yêu cầu và sai số chuẩn P-value $=0.00<0.05$ các trọng số chưa chuẩn hóa đều có ý nghĩa thống kê với độ tin cậy 95\%, nên các biến quan sát dùng để đo lường các khái niệm đạt giá trị hội tụ.

\subsubsection{Uớc lượng các mối quan hẹ}

Kết quả kiểm định mô hình cấu trúc có $\mathrm{P}$-value $=0.00<0.05$. Các chỉ số đều phù hợp với dữ liệu thị trường (Chi-quare/df < 3; CFI, GFI, TLI > 0.9, RMSEA < 0.08)

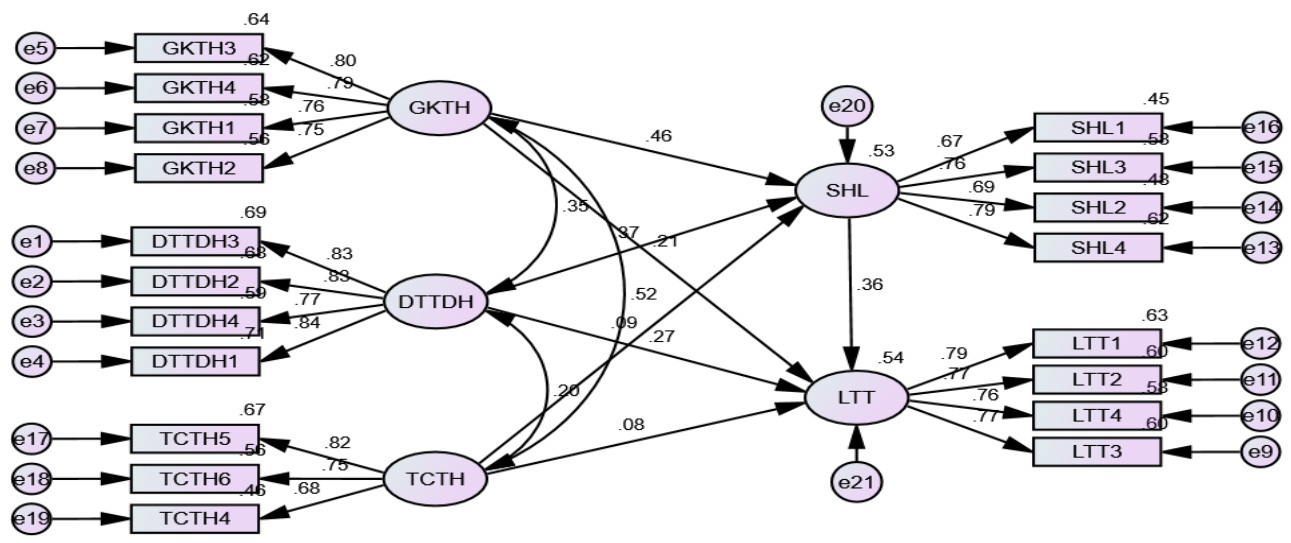

Chi-square $=192.618 ; d f=142 ;$ Chi-square/df $=1.356 ; G F I=0.925 ; T L I=0.974$

$$
C F I=0.978 ; \text { RMSEA }=0.038
$$

Hình 2: Kết quả phân tích SEM mô hình lí thuyết (đã chuẩn hóa)

(Nguồn: Tác giả phân tích số liệu tù phần mền Amos)

Kết quả ước lượng các hệ số hồi quy trong mô hình (bảng 5) cho thấy, ngoại trừ tính cách thương hiệu không tác động lên sự hài lòng, tính cách thương hiệu không tác động lên lòng trung thành do $\mathrm{P}$-value đều lớn hơn 0.05 , tất cả mối tác động còn lại đều có ý nghĩa do P-value đều nhỏ hơn 0.05 . 
Bảng 5. Bảng trọng số hồi quy các mối quan hệ trong mô hình lí thuyết

\begin{tabular}{c|ccccc} 
& $\begin{array}{c}\text { Hệ số chưa } \\
\text { chuẩn hóa }\end{array}$ & $\begin{array}{c}\text { Hệ số chuẩn } \\
\text { hóa }\end{array}$ & S.E. & C.R. & P \\
\hline GKTH $\rightarrow$ SHL & .436 & .458 & .080 & 5.480 & $* * *$ \\
DTTDH $\rightarrow$ SHL & .286 & .370 & .052 & 5.543 & $* * *$ \\
TCTH $\rightarrow$ SHL & .081 & .086 & .071 & 1.139 & .255 \\
GKTH $\rightarrow$ LTT & .193 & .210 & .079 & 2.350 & .019 \\
DTTDH $\rightarrow$ LTT & .201 & .271 & .052 & 3.751 & $* * *$ \\
TCTH $\rightarrow$ LTT & .071 & .078 & .062 & 1.083 & .279 \\
SHL $\rightarrow$ LTT & .343 & .356 & .091 & 3.625 & $* * *$
\end{tabular}

(Nguồn: Tác giả tổng hợp số liệu tù phần mền Amos)

\subsection{Thảo luận kết quả nghiên cứu}

Kết quả nghiên cứu của 5 khái niệm bao gồm: (1) Danh tiếng trường đại học, (2) Tính cách thương hiệu, (3) Gắn kết thương hiệu, (4) Sự hài lòng, (5) Lòng trung thành sinh viên. Hầu hết các thang đo được kế thừa từ các nghiên cứu trước đều đạt độ tin cậy cao và dữ liệu thu thập được phù hợp với thực tế.

Qua kết quả kiểm định giả thuyết bằng mô hình SEM, kết quả đạt được như sau:

Có 5 mối quan hệ có ý nghĩa thống kê khoảng tin cậỵ 95\% và 2 mối quan hệ không có ý nghĩa thống kê. Gắn kết thương hiệu, danh tiếng trường đại học có mối quan hệ có ý nghĩa với sự hài lòng. Gắn kết thương hiệu, danh tiếng trường đại học, sự hài lòng có mối quan hệ có ý nghĩa với lòng trung thành sinh viên. Cự thể:

Thứ nhất, sự hài lòng của sinh viên chịu tác động tích cực từ gắn kết thương hiệu, danh tiếng trường đại học. Phù hợp với sự tồn tại trong nghiên cứu, danh tiếng của trường đại học thể hiện tác động mạnh mẽ đến sự hài lòng (Helm và cộng sự, 2010; Chang, 2013; Su và cộng sự, 2016). Danh tiếng doanh nghiệp của một cơ sở giáo dục đại học có vai trò quan trọng để hình thành hành vi thuận lợi trong số các bên liên quan được đánh giá cao nhất các sinh viên (Su và cộng sự, 2016). Như vậy, khi danh tiếng trường đại học được đánh giá tốt thì sự hài lòng của sinh viên cũng chịu ảnh hưởng tích cực. Khi danh tiếng trường đại học tăng 1 đơn vị thì sự hài lòng của sinh viên tăng 0.370 đơn vị.

Tuy nhiên, kết quả cho thấy gắn kết thương hiệu có tác động mạnh đến sự hài lòng hơn danh tiếng trường đại học. Độ lớn của mối quan hệ sự gắn kết thương hiệu với sự hài lòng $0.458, \mathrm{P}$-value $<0.05$ có ý nghĩa thống kê và đạt độ tin cậy $95 \%$. Phù hợp với phát hiện trước đó hơn nhận thấy sự gắn kết như một yếu tố quyết định lòng trung thành (Yuksel \& cộng sự, 2010; Nyadzayo và cộng sự, 2018) và sự hài lòng (Veasna và cộng sự, 2013). Vì vậy, khi gắn kết thương hiệu tăng 1 đơn vị thì sự hài lòng của sinh viên tẳng 0.458 đơn vị.

Kết quả kiểm định mức độ tác động của mối quan hệ giữa tính cách thương hiệu và sự hài lòng trong mô hình nghiên cứu này là 0.086 , $\mathrm{P}$-value $=0.255>0.05$, như vậy không có ý nghĩa thống kê trong mối quan hệ này.

Thứ hai, lòng trung thành của sinh viên chịu tác động tích cực từ gắn kết thương hiệu, danh tiếng trường đại học và sự hài lòng của sinh viên. Trong đó sự hài lòng có mức độ tác động mạnh mẽ đối với lòng trung thành sinh viên. Sự hài lòng là tiền đề quan trọng của lòng trung thành và cũng đóng vai trò như một người trung gian chính giữa danh tiếng và lòng trung thành (Caruana, 2002; Chang, 2013; Su và cộng sự, 2016). Kết quả phù hợp với nghiên cứu trên cũng nhấn mạnh vào việc xem xét sự hài lòng trong khi kiểm tra lòng trung thành trong khuôn khổ giáo dục đại học. Sự hài lòng được tìm thấy là ảnh hưởng tích cực đến hành vi trung thành của sinh viên với mức độ tác động là 0.356 và hệ số $P$-value $=0.000$ có ý nghĩa thống kê.

Bên cạnh đó, dựa trên mối quan hệ danh tiếng - lòng trung thành, ảnh hưởng của danh tiếng trường đại học đến hành vi hỗ trợ của sinh viên (Sung và Yang, 2008) danh tiếng trường đại học có mối quan hệ cùng chiều với lòng trung thành sinh viên thể hiện qua kết quả kiểm định 0.271 , hệ số $\mathrm{P}$-value $<0.05$ mối quan hệ này có ý nghĩa thống kê.

Gắn kết thương hiệu cũng có mối quan hệ cùng chiều với lòng trung thành của sinh viên. Độ lớn của mối quan hệ này với lòng trung thành của sinh viên 0.210 với mức ý nghĩa thống kê $\mathrm{P}$-value $=0.019<0.05$ đạt độ tin cậy $95 \%$. Những trải nghiệm tích cực và sự gắn kết gợi lên tâm lý tích cực của người tiêu dùng-đề 
cập đến thương hiệu. Do đó, sự gắn kết với thương hiệu góp phần tạo nên một tăng cam kết hành vi, là một chỉ số của thương hiệu lòng trung thành (Levy \& Hino, 2016). Do đó, sự gắn bó với thương hiệu tăng cường lòng trung thành với thương hiệu (Jahn \& Kunz, 2014).

Tương tự mối quan hệ giữa sự hài lòng và tính cách thương hiệu, mối quan hệ giữa tính cách thương hiệu và lòng trung thành trong mô hình nghiên cứu này có chỉ số $\mathrm{P}$-value $=0.279>0.05$, mối quan hệ này không có ý nghĩa thống kê

Bảng 6. Kết quả tóm tắt kiểm định các mối quan hệ trong mô hình lí thuyết

\begin{tabular}{|l|l|c|}
\hline \multicolumn{2}{|c|}{ Giả thuyết } & Kết quả \\
\hline H1 & $\begin{array}{l}\text { Danh tiếng trường đại học có ảnh hưởng tích cực đến sự hài lòng }(\mathrm{H} 1 \mathrm{a}) \text { và ảnh hưởng } \\
\text { tích cực đến lòng trung thănh của sinh viên }(\mathrm{H} 1 \mathrm{~b})\end{array}$ & Chấp nhận \\
\hline $\mathrm{H} 2$ & $\begin{array}{l}\text { Gắn kết thương hiệu có ảnh hưởng tích cực đến sự hài lòng }\left(\mathrm{H}_{2 \mathrm{a}}\right) \text { và ảnh hưởng tích } \\
\text { cực đến lòng trung thành của sinh viên }\left(\mathrm{H}_{2 b}\right) .\end{array}$ & Chấp nhận \\
\hline H3 & $\begin{array}{l}\text { Tính cách thương hiệu có ảnh hưởng tích cực đến sự hài lòng }\left(\mathrm{H}_{3 \mathrm{a}}\right) \text { và ảnh hưởng tích } \\
\text { cực đến lòng trung thành của sinh viên }\left(\mathrm{H}_{3 \mathrm{~b}}\right) .\end{array}$ & Bác bỏ \\
\hline H4 & Sự hài lòng của sinh viên ảnh hưởng tích cực đến lòng trung thành của sinh viên & Chấp nhận \\
\hline
\end{tabular}

\section{HÀM Ý QUẢN TR!}

Nâng cao lòng trung thành sinh viên là điều cần thiết đối với các cơ sở giáo dục đại học. Lòng trung thành của sinh viên sẽ được thể hiện qua việc lựa chọn khóa học tiếp theo tại trường, có thể sinh viên sẽ tiếp tục lựa chọn trường để học lên cao học. Bên cạnh đó, sinh viên còn sẽ giới thiệu trường cho các sinh viên khác, bạn bè hay người thân của họ đang có ý định học tập tại môi trường đại học.

Thứ nhất, sự hài lòng có tác động tích cực và mạnh mẽ đến lòng trung thành của sinh viên. Cho nên, các nhà quản lý thương hiệu trường đại học nên chú trọng yếu tố hài lòng của sinh viên bằng cách xem xét cải thiện phương pháp giảng dạy cũng như cải thiện chất lượng bài giảng, phản hồi nhanh chóng các thắc mắc của sinh viên để gia tăng sự hài lòng sinh viên từ đó là tiền đề để thúc đẩy lòng trung thành của sinh viên. Phía nhà trường cần phải đầu tư phối hợp với giảng viên kiểm tra chất lượng bài giảng đã phù hợp với chuẩn đầu ra hay chưa. Thường xuyên khảo sát đánh giá sự hài lòng của sinh viên. Phân bổ thêm nhân lực nhận phản hồi và giải đáp thắc mắc trực tiếp tại trường và trực tuyến trên các website, kênh truyền thông của trường. Nâng cấp chất lượng các dịch vụ như các thiết bị truy cập tra cứu, Internet. Sự hài lòng là yếu tố quyết định quan trọng nhất đối với sự cống hiến của các cựu sinh viên. Bên cạnh đó để đảm bảo tiêu chuẩn chất lượng ở trường học, nhà trường cần tăng cường đầu tư cơ sở hạ tầng nhằm nâng cao khả năng cung cấp dịch vụ, đảm bảo chất lượng dịch vụ đúng theo tiêu chuẩn.

Thứ hai, nghiên cứu đã chứng minh danh tiếng trường đại học có mối quan hệ đến lòng trung thành của sinh viên. Các nhà quản trị thương hiệu trường đại học nên tích cực công tác hoạch định truyền thông để nâng cao giá trị thương hiệu cũng như danh tiếng thương hiệu không chỉ trong mắt sinh viên mà còn đối với các cá nhân khác (phụ huynh/ doanh nghiệp đối tác/ cộng đồng xã hội). Liên tục đổi mới phương thức giảng dạy, cập nhật xu hướng giáo dục mới phù hợp với nền giáo dục Việt Nam. Đưa ra các khoảng học bổng hổ trợ sinh viên khuyến khích sinh viên học tập. Đào tạo nguồn lực sinh viên đầu ra có năng lực, được trang bị đầy đủ cách kĩ năng mềm đáp ứng tiêu chí mà nhà tuyển dụng đưa ra, lan rộng hinhf ảnh daanh . Sinh viên có thành tích tốt, kĩ năng làm việc và tác phong tốt thể hiện chất lượng đào tạo của nhà trường. Thể hiện tầm ảnh hưởng của nhà trường với các doanh nghiệp đối tác, cộng đồng bằng cách mời các doanh nhân, các diễn giả có uy tín/danh tiếng về trường truyền cảm hứng, năng lượng tích cực tạo ra giá trị chung cho cộng đồng. Danh tiếng trường đại học không chỉ thu hút sự quay lại của các sinh viển cũ mà còn là co sở để lựa chọn trường của sinh viên mới, là những yếu tố ảnh hưởng mạnh nhất đến việc lựa chọn trường của sinh viên. Bên cạnh việc triển khai nâng cao danh tiếng, trường đại học cần phải kiểm soát triệt để các khủng hoảng ảnh hưởng đến danh tiếng của trường, tạo cái nhìn không tốt của sinh viên đối với trường đại học.

Thứ ba, chú trọng vào công tác truyền thông xã hội. Internet có thể hoạt động như một công cụ phục vụ rất hiệu quả cho doanh nghiệp, đặc biệt là nhà trường. Nhà trường cần chuẩn bị thông tin phản hồi sinh viên trên truyền thông. Từ đó, sinh viên sẽ dễ dàng kết nối với nhà trường trên mọi khía cạnh, đồng thời nắm rõ thông tin cần thiết mà nhà trường đang thông báo. Thường xuyên tổ chức các buổi hội thảo, hướng nghiệp 
hoặc khởi nghiệp cho sinh viên, nội dung hội thảo mang lại lợi ích cho sinh viên hay cách hướng dẫn sinh viên khởi nghiệp, tạo điều kiện cho sinh viên khởi nghiệp. Ngoài ra, các trường đại học nên tổ chức các buổi giao lưu giữa sinh viên và giảng viên, hoặc buổi chia sẻ theo chủ đề mà sinh viên cần trao dồi, những buổi trao đổi sẽ tạo nên sự gắn kết của sinh viên đối với thầy cô của trường.

Cuối cùng, duy trì mối quan hệ gắn bó mật thiết với học sinh - sinh viên là yếu tố quan trọng để tăng lòng trung thành của sinh viên. Walt Disney từng nói, "Hãy đối đãi với khách hàng tốt đến mức mà họ muốn quay lại thêm lần nữa và có thể rủ thêm bạn bè của họ”. Tạo dựng được sự gắn bó giữa nhà trường và sinh viên làm tăng hiệu quả của marketing truyền miệng (word of mouth) - phương pháp marketing hiệu quả bậc nhất. Và việc đầu tiên để tạo mối quan hệ tốt với sinh viên phải có một lực lượng giảng viên có tâm, có trách nhiệm. Nhà trường nên thường xuyên tổ chức các khóa học nâng cao kiến thức và kỹ năng của giảng viên. Đảm bảo những cam kết luôn mang lại lợi ích cho sinh viên, luôn bảo mật thông tin của sinh viên. Ngoài ra, cần đa dạng hóa các kênh chăm sóc sinh viên, chăm sóc trực tiếp tại nhà trường và chăm sóc gián tiếp qua email, điện thoại.

\section{TÀI LIỆU THAM KHẢO}

Aaker, D. (1991). Managing brand equity. New York, NY: The Free Press.

Aaker, J. (1997). Dimensions of brand personality. Journal of Marketing 34, 347-356.

Aaker, J.L., V. Benet-Martinez, and J. Garolera. (2001). Consumption symbols as carriers of culture: A study of Japanese and Spanish. Journal of Personality and Social Psychology 81, 492-508.

Alessandri, S.W., S.U. Yang, and D.F. Kinsey. 2006. (2006). An integrative approach to university visual identity and reputation. Corporate Reputation Review 9, 258-270.

Alexandris, K., C. Kouthouris, and A. Meligdis. (2006). Increasing customers' loyalty in a skiing resort: The contribution of place attachment and service quality. International Journal of Contemporary Hospitality Management 18, 414-425.

Alves, H. (2011). The measurement of perceived value in higher education: a unidimensional approach. The Service Industries Journal, 1943-1960.

Alves, H., and M. Raposo. (2010). The influence of university image on student behaviour. International Journal of Educational Management 24, 73-85.

Alves, H., and M. Raposo. (2006). Conceptual model of student satisfaction in higher education. Total Quality Management 18, 571-588.

Amerigo, M., and J.I. Aragones. (1990). Residential satisfaction in council housing. Journal of Environmental Psychology 10, 313-325.

Andreassen, T.W., and B. Lindestad. (1998). Customer loyalty and complex services: The impact of corporate image on quality customer satisfaction and loyalty for customers with varying degrees of service expertise. International Journal of Service Industry Management 9, 7-23.

Athiyaman, A. (1997). Linking student satisfaction and service quality perceptions: The case of university education. European Journal of Marketing 31, 528-540.

Bekk, M., M. Spörrle, M. Landes, and K. Moser. (2017). Traits grow important with increasing age: Customer age, brand personality and loyalty. Journal of Business Economics 87, 511-531.

Brookes, M. (2003). Higher education: Marketing in a quasi-commercial service industry. International Journal of Nonprofit and Voluntary Sector Marketing 8, 134-142.

Brown, R.M., and T.W. Mazzarol. (2009). The importance of institutional image to student satisfaction and loyalty within higher education. Higher Education 58, 81-95.

Bunzel, D. (2007). Universities sell their brands. Journal of Product \& Brand Management 16, 152-153. 
182 MỐI QUAN HỆ GIŨA DANH TIẾNG TRƯỜNG ĐẠI HỌC, TÍNH CÁCH THƯƠNG HIẸU, GẮN KẾT THƯƠNG HIỆU VÀ LÒNG TRUNG THÀNH CỦA SINH VIÊN TẠI THÀNH PHỐ HỔ CHÍ MINH

C, V. (2015). Brand evaluation, satisfaction and trust as predictors of brand loyalty: the mediator-moderator effect of brand relationships. Journal of Consumer Marketing, 32, 405 - 421.

Caruana, A. (1997). Corporate reputation: Concept and measurement. Journal of Product \&Brand Management, 6, $109-118$.

Carvalho, S.W., and M.O. Mota. (2010). The role of trust in creating value and student loyalty in relational exchanges between higher education institutions and their students. Journal of Marketing for Higher Education 20, 145165.

Chang, K. (2013). How reputation creates loyalty in the restaurant sector. International Journal of Contemporary Hospitality Management 25, 536-557.

Clardy, A. (2012). Organizational reputation: Issues in conceptualization and measurement. Corporate Reputation Review, 15, 285-303.

Curtis, T., R. Abratt, and W. Minor. . (2009). Corporate brand management in higher education: The case of ERAU. Journal of Product \& Brand Management 18, 404-413.

Đào Văn Khanh. (2004). Thương hiệu đại học Việt Nam, tại sao không? Tạp chí khoa học, Đại học Cần Tho, số 1, 164-171.

Dennis, C., S. Papagiannidis, E. Alamanos, and M. Bourlakis. (2016). The role of brand attachment strength in higher education. Journal of Business Research 69, 3049-3057.

DeShields Jr., O.W., A. Kara, and E. Kaynak. . (2005). Determinants of business student satisfaction and retention in higher education: Applying Herzberg's two-factor theory. International Journal of Educational Management $19,128-139$.

Dowling, G. (2016). Winning the reputation game: Creating stakeholder value and competitive advantage. Cambridge (USA): The MIT Press.

Elliott, K.M., and D. Shin. . (2002). Student satisfaction: An alternative approach to assessing this important concept. Journal of Higher Education Policy and Management 24, 197-209.

Finch, D., C. Hillenbrand, and H. Rubin. 2015. (2015). Proximity, strategic groups and reputation: An exploratory study of reputation in higher education. Corporate Reputation Review 18, 174-194.

Fornell, C., and D.F. Larcker. (1981). Evaluating structural equation models with unobservable variables and measurement error. Journal of Marketing Research 18, 39-50.

G, D. (2014). Impacts of retail brand personality and self-congruity on store loyalty: the moderating role of gender. Retail Consum Serv 21, 130-138.

Hemsley-Brown, J., and I. Oplatka. (2006). Universities in a competitive global marketplace: A systematic review of the literature on higher education marketing. International Journal of Public Sector Management 19, 316338.

Hennig-Thurau, T., M.F. Langer, and U. Hansen. (2001.). Modeling and managing student loyalty: An approach based on the concept of relationship quality. Journal of Service Research 3, 331-344.

Jillapalli, R.K., and R. Jillapalli. (2014). Do professors have customerbased brand equity? Journal of Marketing for Higher Education 24, 22-40.

Levy, S., and Hino, H. (2016). Emotional brand attachment: A factor in customer-bank relationships. The International Journal of Bank Marketing 34, 136-150.

Louis, D., \& Lombart, C. (2010). Impact of brand personality on three major relational consequences (trust, attachment, and commitment to the brand). JOURNAL of Product \& BRAND MANAGEMENT,19, 114-130.

Loureiro, S.M.C., E.M. Sarmento, and G. Le Bellego. (2017). The effect of corporate brand reputation on brand attachment and brand loyalty. Automobile sector. Cogent Business \& Management 4, 2-10.

Nguyễn Ngọc Hiền. (2020). Phân tích dũ liệu trong kinh doanh. TP HCM: NXB. Đại học Công nghiệp TP. HCM. 


\section{MỐI QUAN HỆ GIỬA DANH TIẾNG TRƯỜNG ĐẠI HỌC, TÍNH CÁCH THƯƠNG HIẸU, GẮN KẾT 183 THƯƠNG HIÊUU VÀ LÒNG TRUNG THÀNH CỦA SINH VIÊN TẠI THÀNH PHỐ HỔ CHÍ MINH}

Nguyen, N., and G. LeBlanc. (2001). Image and reputation of higher education institutions in students' retention decisions. International Journal of Educational Management 15, 303-311.

Oliver, R. (1997). Satisfaction: A behavioral perspective on the consumer. New York: Irwin/McGraw-Hill.

Opoku, R.A., M. Hultman, and E. Saheli-Sangari. (2008). Positioning market space: The evaluation of Swedish universities' online brand personalities. Journal of Marketing for Higher Education 18, 124-144.

Rampl, L .V, \& Kenning, P. (2014). Employer brand trust and affect: linking brand personality to employer brand attractiveness. European Journal of Marketing, 48(, 218-236.

Rauschnabel, P.A., N. Krey, B.J. Babin, and B.S. Ivens. ( 2016). Brand management in higher education: The university brand personality scale. Journal of Business Research 69, 3077-3086.

Selnes, F. (1993). An examination of the effect of product performance on brand reputation, satisfaction and loyalty. European Journal of Marketing 27, 19-35.

Số liệu thống kê giáo dục đại học năm học 2018 - 2019. (2020, 04 28). Được truy lục từ Bộ giáo dục và đào tạo: https://moet.gov.vn/thong-ke/Pages/thong-ko-giao-duc-dai-hoc.aspx?ItemID=6636

Su, L., S.R. Swanson, S. Chinchanachokchai, M.K. Hsu, and X. Chen. (2016). Reputation and intentions: The role of satisfaction, identification, and commitment. Journal of Business Research 69, 3261-3269.

Sung, M., and S.U. Yang. (2008). Toward the model of university image: The influence of brand personality, external prestige, and reputation. Journal of Public Relations Research 20, 357-376.

Sung, Y., and S.F. Tinkham. (2005). Brand personality structures in the United States and Korea: Common and culture-specific factors. Journal of Consumer Psychology 15, 334-350.

Watkins, B. \&. (2013). Assessing university brand personality through logos: An analysis of the use of academics and athletics in university branding. Journal. Journal of Marketing for Higher Education, 23, 15-33.

Yuksel, A., Yuksel, F., \& Bilim, Y. (2010). Destination attachment: Effectives on customers satisfaction and cognitive, affective and conative loyalty. Tourism Management, 31, 274-284.

Zentes, J. D.-K. (2008). Brand personality of retailers-An analysis of its applicability and its effect on store loyalty. The International Review of Retail, Distribution and Consumer Research 18, 167-184.

Ngày nhận bài: 11/05/2021

Ngày chấp nhận đăng: 18/06/2021 